TITLE:

\title{
Variant ALDH2 is associated with accelerated progression of bone marrow failure in Japanese Fanconi anemia patients
}

\section{$\operatorname{AUTHOR}(\mathrm{S}):$}

Hira, Asuka; Yabe, Hiromasa; Yoshida, Kenichi; Okuno, Yusuke; Shiraishi, Yuichi; Chiba, Kenichi; Tanaka, Hiroko; ... Matsuo, Keitaro; Takata, Minoru; Yabe, Miharu

\section{CITATION:}

Hira, Asuka ... [et al]. Variant ALDH2 is associated with accelerated progression of bone marrow failure in Japanese Fanconi anemia patients. Blood 2013

\section{ISSUE DATE:}

2013-09-13

URL:

http://hdl.handle.net/2433/178719

\section{RIGHT:}

〔 2013 American Society of Hematology; この論文は出版社版でありま せん。引用の際には出版社版をご確認ご利用ください。; This is not the published version. Please cite only the published version. 


\section{Variant ALDH2 is associated with accelerated progression of bone marrow failure in}

\section{Japanese Fanconi anemia patients}

Asuka Hira ${ }^{1}$, Hiromasa Yabe $^{2}$, Kenichi Yoshida ${ }^{3}$, Yusuke Okuno ${ }^{3}$, Yuichi Shiraishi ${ }^{4}$, Kenichi Chiba $^{4}$, Hiroko Tanaka ${ }^{5}$, Satoru Miyano ${ }^{4,5}$, Jun Nakamura ${ }^{6}$, Seiji Kojima ${ }^{7}$, Seishi Ogawa ${ }^{3,8}$,

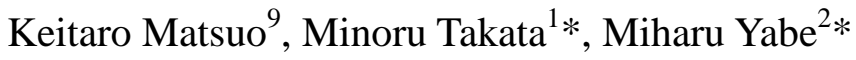

${ }^{1}$ Laboratory of DNA Damage Signaling, Dept of Late Effects Studies, Radiation Biology Center, Kyoto University, Kyoto 606-8501, Japan.

${ }^{2}$ Department of Cell Transplantation and Regenerative Medicine, Tokai University School of Medicine, Isehara 259-1193, Japan.

${ }^{3}$ Cancer Genomics Project, Graduate School of Medicine, The University of Tokyo, Tokyo 113-8655, Japan

${ }^{4}$ Laboratory of DNA Information Analysis, Human Genome Center, Institute of Medical Science, The University of Tokyo, Tokyo, Japan

${ }^{5}$ Laboratory of Sequence Analysis, Human Genome Center, Institute of Medical Science, The University of Tokyo, Tokyo, Japan

${ }^{6}$ Department of Environmental Sciences and Engineering, University of North Carolina at Chapel Hill, Chapel Hill, NC 27599, USA

${ }^{7}$ Department of Pediatrics, Nagoya University Graduate School of Medicine, Nagoya 4668550, Japan

${ }^{8}$ Department of Pathology and Tumor Biology, Graduate School of Medicine, Kyoto University, Kyoto 606-8501, Japan 
${ }^{9}$ Department of Preventive Medicine, Kyushu University Faculty of Medical Sciences, Fukuoka, 812-8582, Japan

Running head: ALDH2 variant impacts bone marrow failure in FA

Conflict of interest statement: Authors declare that there is no conflict of interest.

Text word count: 1166

Abstract word count: 149

The number of figures and tables: 2

The number of references: 25 


\section{Key points}

- We found the defective ALDH2 variant is associated with accelerated progression of bone marrow failure in Japanese Fanconi anemia patients.

- The data support the view that aldehydes are an important source of genotoxicity in the human hematopoietic system. 


\section{Abstract}

Fanconi anemia (FA) is a severe hereditary disorder with defective DNA damage response and repair. It is characterized by phenotypes including progressive bone marrow failure (BMF), developmental abnormalities, and increased occurrence of leukemia and cancer. Recent studies in mice have suggested that the FA proteins might counteract aldehydeinduced genotoxicity in hematopoietic stem cells. Nearly half of the Japanese population carries a dominant negative allele (rs671) of the aldehyde-catalyzing enzyme ALDH2 (acetaldehyde dehydrogenase 2), providing an opportunity to test this hypothesis in humans. We examined 64 Japanese FA patients, and found that the $A L D H 2$ variant is associated with accelerated progression of BMF, while birth weight or the number of physical abnormalities was not affected. Moreover, malformations at some specific anatomic locations were observed more frequently in $A L D H 2$-deficient patients. Our current data indicate that the level of ALDH2 activity impacts pathogenesis in FA, suggesting the possibility of a novel therapeutic approach. 


\section{Introduction}

Fanconi anemia (FA) is a genomic instability disorder with phenotypes including progressive bone marrow failure (BMF), developmental abnormalities, and increased occurrence of leukemia and cancer ${ }^{1}$. To date 16 genes have been implicated in FA, and their products form a common DNA repair network ("FA pathway")"2,3 Since FA cells are hypersensitive to DNA interstrand cross-links (ICLs), the FA pathway has been considered to be involved in the repair of $\mathrm{ICLs}^{2,3}$. However, it remains unclear what type of endogenous DNA damage is repaired through the FA pathway. Recent studies have suggested that FA cells are also sensitive to aldehydes ${ }^{4}$, which may create DNA adducts including ICLs or DNA-protein crosslinks. Furthermore, double knockout mice deficient in Fancd2 and Aldh2, but neither of the single mutant mice, display an accelerated development of leukemia and $\mathrm{BMF}^{5,6}$. On the other hand, Fanc-deficient mice in general do not fully recapitulate the human FA phenotype, including overt $\mathrm{BMF}^{7}$. Thus, the role of aldehydes in the pathogenesis of human FA is still uncertain.

ALDH2 deficiency resulting from a Glu504Lys substitution (rs671, hereinafter referred to as the A allele) is highly prevalent in East Asian populations. The A allele (Lys504) acts as a dominant negative, since the variant form can suppress the activity of the Glu504 form (G allele) in GA heterozygotes by the formation of heterotetramers ${ }^{8}$. Individuals with the A variant experience flushing when drinking alcohol, and have an elevated risk of esophageal cancer with habitual drinking ${ }^{9}$. Because the frequency of the A allele is close to $50 \%$ in the Japanese population at large, some Japanese FA patients are expected to be deficient in $A L D H 2$. We thus set out to determine the $A L D H 2$ status in a collection of Japanese FA patients.

\section{Methods}


The onset of BMF was defined according to the criteria used in the International Fanconi Anemia Registry (IFAR) study ${ }^{10}$. Criteria for diagnosis of aplastic anemia and other conditions are described in Supplemental Methods. We observed physical abnormalities characteristic of FA, including skin abnormalities (hyperpigmentation and café au lait spots), low birth weight, growth defects, and malformations affecting skeletal systems and deep organs. Extensive malformation was defined as the involvement of at least three sites including at least one deep organ ${ }^{11}$. Mutation analysis of FANCA/FANCC/FANCG genes $^{12}$, ALDH2 genotyping ${ }^{13}$, Multiplex Ligation-mediated Probe Amplification (MLPA) test for FANCA (Falco), and whole exome sequencing (WES) ${ }^{14}$ were done as previously described. Details are provided as supplemental methods. Development of BMF or acute myeloid leukemia (AML)/myelodysplasia (MDS) was analyzed by the Kaplan-Meier method or the cumulative incidence method $^{15,16}$, respectively, since competing events (e.g., death and stem cell transplantation (SCT)) existed in AML/MDS but not in BMF. This study was approved by the Research Ethics Committee of the Tokai University Hospital and Kyoto University. We obtained family informed consent from all subjects involved in this work.

\section{Results and Discussion}

All of the patients in this study ( $n=64$, supplemental Table 1 ) were referred to the Tokai University Hospital because of pancytopenia, in some cases with MDS or leukemia. The clinical diagnosis of FA was made based on clinical presentation and Diepoxybutane (DEB)induced chromosome fragility tests in peripheral blood lymphocytes ${ }^{17}$, except for three cases in which the DEB test was negative due to FANCA reversion mosaicism (supplemental Table 1 and 2). Most of the patients underwent allogeneic SCT, indicating that our patients probably represent a FA population with relatively severe hematological symptoms.

To determine which FA gene was mutated in each of these patients, we applied combinations of PCR-based methods $(n=26)$, the MLPA test for FANCA mutations $(n=44)$, 
and WES ( $\mathrm{n}=29)$. In our WES analysis, more than $90 \%$ of the $50 \mathrm{Mb}$ target sequences were analyzed by greater than ten independent reads (data not shown). 59 patients were found to have a mutation in FA genes in at least one allele, but 5 of them were mutation-free in the known 16 FA genes, even after WES (Table 1 and supplemental Table 1). These unclassified cases might be caused by large deletions or intronic mutations that are difficult to detect with these methods ${ }^{18}$, or possibly mutations in a novel FA gene.

We determined the ALDH2 genotype in our series of 64 patients (Table 1 and supplemental Table 1). The distribution of the $A L D H 2$ variant alleles appeared not significantly different from the reported allele frequencies in the healthy Japanese population $^{13}$. The occurrence of leukemia and/or MDS was also not significantly different between patients with GA and GG genotypes. Strikingly, however, we found that progression of BMF was accelerated in heterozygous carriers of the variant $\mathrm{A}$ allele compared to homozygous GG patients (Figure 1A and B). Moreover, the three individuals carrying AA alleles developed MDS with BMF at a very young age (Figure 1A and B). None of these three patients belonged to FA-D1 or FA-N, the FA subgroups with severe symptoms ${ }^{19,20}$. Patient number 3 had biallelic frameshift mutations (S115AfsX11) in FANCP/SLX4. By contrast, of the FA-P patients that have previously been reported, none have displayed particularly severe symptoms ${ }^{21-23}$.

FA is a heterogeneous disorder, and our cohort of patients is quite heterogeneous in terms of complementation groups and types of mutations (Table 1). In order to reduce some of the variability, we selected only the FANCA patients having nonsense, frameshift, or large deletion mutations identified at both alleles, $(\mathrm{n}=12$, supplemental Table 1$)$, and repeated the analysis. A patient with probable FANCA reversion (patient number 55) was excluded. In this subset of patients, a highly significant statistical difference was reproduced in BMF progression (Figure 1C) but not in AML/MDS development (data not shown). 
We could not detect any significant difference in terms of \% birth weight (Figure 1D) or number of physical abnormalities (Figure 1E) that correlated with the $A L D H 2$ genotypes. However, a significant difference was observed in the incidence of each class of malformations in the case of radial, cardiovascular, skeletal, or kidney anomalies, and in the incidence of extensive malformation (Figure 1F).

In conclusion, our current data indicate that endogenous aldehydes are an important source of genotoxicity in the human hematopoietic system, and the FA pathway counteracts them. If the FA pathway is compromised, hematopoietic stem cells (HSCs) likely accumulate aldehyde-induced DNA damage, resulting in BMF due to p53/p21-mediated cell death or senescence $^{6,24}$. Consistent with this model, a recent study showed that the HSCs in aldh2/fancd2 double knockout mice accumulate more DNA damage than HSCs in either of the single knockout mice ${ }^{6}$. Since some $A L D H 2$-proficient FA patients developed BMF early, other modifier genes or environmental factors might affect levels of aldehydes or other genotoxic substances. Interestingly, our data predict that Japanese FA patients in general develop BMF at an earlier age compared to patients of other ethnic origins. We need to establish a Japanese FA registry similar to IFAR to test whether this is true or not. Finally, it seems worth considering $A L D H 2$ agonists such as Alda- 1 as protective drugs against BMF in FA patients. Alda-1 can stimulate the enzymatic activity of both the normal and variant ALDH2 ${ }^{25}$, suggesting that Alda- 1 or a similar drug could be beneficial even for $A L D H 2$ proficient FA cases. 
Acknowledgments: We thank the individual patients and families in the study who made this work possible; Dr. K.J. Patel (University of Cambridge) for communicating unpublished results; Dr. James Hejna (Graduate School of Biostudies, Kyoto University) for critical reading of the manuscript and English editing; Mr Naoya Suzuki and Drs. Akira Niwa and Megumu Saito (CiRA, Kyoto University) for discussion; Ms. Fumiko Tsuchida, Emi Uchida, Sumiyo Ariga, Chinatsu Ohki and Mao Hisano for expert technical assistance. This work was supported by grants from the Ministry of Health, Labor and Welfare, and grants from the Ministry of Education, Culture, Sports, Science and Technology (MEXT).

Contributions: M.Y. and H.Y. examined DEB-induced chromosome aberrations, carried out MLPA testing, and analyzed clinical records. K.Y., Y.O., Y.S., K.C., H.K, S.M., S.K., and S.O. performed whole exome sequencing and analyzed sequence data. A.H. validated exome data, and carried out genotyping, and A.H, M.Y., H.Y., K.M., J.N., and M.T. analyzed data. M.Y., M.T., and K.M. wrote the paper.

Conflicts of Interest disclosure: The authors declare that they have no competing financial interests.

Correspondence: Minoru Takata, Laboratory of DNA Damage Signaling, Dept of Late Effects Studies, Radiation Biology Center, Kyoto University, Kyoto 606-8501, Japan. Phone: +81-75-753-7563, Fax: +81-75-753-7564; E-mail: mtakata@house.rbc.kyoto-u.ac.jp or Miharu Yabe网 Department of Cell Transplantation and Regenerative Medicine, Tokai University School of Medicine, Isehara 259-1193, Japan. Phone: +81-463-93-1121; Fax: +81463-93-8607; E-mail: miharu@is.icc.u-tokai.ac.jp 


\section{References}

1. Auerbach AD. Fanconi anemia and its diagnosis. Mutat Res. 2009;668(1-2):4-10.

2. Kim H, D'Andrea AD. Regulation of DNA cross-link repair by the Fanconi anemia/BRCA pathway. Genes Dev. 2012;26(13):1393-1408.

3. Kottemann MC, Smogorzewska A. Fanconi anaemia and the repair of Watson and Crick DNA crosslinks. Nature. 2013;493(7432):356-363.

4. Ridpath JR, Nakamura A, Tano K, et al. Cells deficient in the FANC/BRCA pathway are hypersensitive to plasma levels of formaldehyde. Cancer Res. 2007;67(23):11117-11122.

5. Langevin F, Crossan GP, Rosado IV, Arends MJ, Patel KJ. Fancd2 counteracts the toxic effects of naturally produced aldehydes in mice. Nature. 2011;475(7354):53-58.

6. Garaycoechea JI, Crossan GP, Langevin F, Daly M, Arends MJ, Patel KJ. Genotoxic consequences of endogenous aldehydes on mouse haematopoietic stem cell function. Nature. 2012;489:571-575.

7. Parmar K, D'Andrea A, Niedernhofer LJ. Mouse models of Fanconi anemia. Mutat Res. 2009;668(12):133-140.

8. Crabb DW, Edenberg HJ, Bosron WF, Li TK. Genotypes for aldehyde dehydrogenase deficiency and alcohol sensitivity. The inactive ALDH2(2) allele is dominant. J Clin Invest. 1989;83(1):314-316.

9. Matsuo K, Hamajima N, Shinoda M, et al. Gene-environment interaction between an aldehyde dehydrogenase-2 (ALDH2) polymorphism and alcohol consumption for the risk of esophageal cancer. Carcinogenesis. 2001;22(6):913-916.

10. Butturini A, Gale RP, Verlander PC, Adler-Brecher B, Gillio AP, Auerbach AD. Hematologic abnormalities in Fanconi anemia: an International Fanconi Anemia Registry study. Blood. 1994;84(5):16501655.

11. Guardiola P, Pasquini R, Dokal I, et al. Outcome of 69 allogeneic stem cell transplantations for Fanconi anemia using HLA-matched unrelated donors: a study on behalf of the European Group for Blood and Marrow Transplantation. Blood. 2000;95(2):422-429.

12. Tachibana A, Kato T, Ejima Y, et al. The FANCA gene in Japanese Fanconi anemia: reports of eight novel mutations and analysis of sequence variability. Hum Mutat. 1999;13(3):237-244.

13. Matsuo K, Wakai K, Hirose K, Ito H, Saito T, Tajima K. Alcohol dehydrogenase 2 His47Arg polymorphism influences drinking habit independently of aldehyde dehydrogenase 2 Glu487Lys polymorphism: analysis of 2,299 Japanese subjects. Cancer Epidemiol Biomarkers Prev. 2006;15(5):1009-1013.

14. Kunishima S, Okuno Y, Yoshida K, et al. ACTN1 mutations cause congenital macrothrombocytopenia. Am J Hum Genet. 2013;92(3):431-438.

15. Gray RJ. A class of K-sample tests for comparing the cumulative incidence of a competing risk. Ann Stat. 1988;16:1141-1154.

16. Klein JP, Rizzo JD, Zhang MJ, Keiding N. Statistical methods for the analysis and presentation of the results of bone marrow transplants. Part I: unadjusted analysis. Bone Marrow Transplant. 2001;28(10):909-915. 17. Auerbach AD, Rogatko A, Schroeder-Kurth TM. International Fanconi Anemia Registry: relation of clinical symptoms to diepoxybutane sensitivity. Blood. 1989;73(2):391-396.

18. Chandrasekharappa SC, Lach FP, Kimble DC, et al. Massively parallel sequencing, ArrayCGH and RNA-Seq technologies provide a comprehensive molecular diagnosis of Fanconi anemia. Blood. 2013;121(22):e138-148.

19. Wagner JE, Tolar J, Levran O, et al. Germline mutations in BRCA2: shared genetic susceptibility to breast cancer, early onset leukemia, and Fanconi anemia. Blood. 2004;103(8):3226-3229.

20. Reid S, Schindler D, Hanenberg H, et al. Biallelic mutations in PALB2 cause Fanconi anemia subtype FA-N and predispose to childhood cancer. Nat Genet. 2007;39(2):162-164.

21. Kim Y, Lach FP, Desetty R, Hanenberg H, Auerbach AD, Smogorzewska A. Mutations of the SLX4 gene in Fanconi anemia. Nat Genet. 2011;43(2):142-146.

22. Stoepker C, Hain K, Schuster B, et al. SLX4, a coordinator of structure-specific endonucleases, is mutated in a new Fanconi anemia subtype. Nat Genet. 2011;43(2):138-141.

23. Schuster B, Knies K, Stoepker C, et al. Whole exome sequencing reveals uncommon mutations in the recently identified Fanconi anemia gene SLX4/FANCP. Hum Mutat. 2013;34(1):93-96.

24. Ceccaldi R, Parmar K, Mouly E, et al. Bone Marrow Failure in Fanconi Anemia Is Triggered by an Exacerbated p53/p21 DNA Damage Response that Impairs Hematopoietic Stem and Progenitor Cells. Cell Stem Cell. 2012;11(1):36-49.

25. Chen CH, Budas GR, Churchill EN, Disatnik MH, Hurley TD, Mochly-Rosen D. Activation of aldehyde dehydrogenase-2 reduces ischemic damage to the heart. Science. 2008;321(5895):1493-1495. 
Table 1. Summary of genotypes and clinical characteristics of the patients studied.

\begin{tabular}{|c|c|c|c|c|}
\hline & & \multicolumn{3}{|c|}{ ALDH2 genotype } \\
\hline & Total & GG & GA & $\mathrm{AA}$ \\
\hline Number of cases & 64 & 36 & 25 & 3 \\
\hline \multicolumn{5}{|l|}{ Mutated FA gene ${ }^{A}$} \\
\hline FANCA & 39 & $26^{\mathrm{B}}$ & 11 & 2 \\
\hline FANCG & 15 & 7 & 8 & - \\
\hline FANCI & 2 & - & 2 & - \\
\hline FANCM & 1 & - & 1 & - \\
\hline FANCP & 2 & - & 1 & 1 \\
\hline Unknown & 5 & 3 & 2 & - \\
\hline \multicolumn{5}{|l|}{ Disease } \\
\hline $\mathrm{AA}$ & 2 & 2 & - & - \\
\hline SAA & 40 & 21 & 19 & - \\
\hline MDS/AML & 22 & 13 & 6 & $3^{\mathrm{C}}$ \\
\hline Tongue cancer & 2 & 1 & 1 & - \\
\hline \multicolumn{5}{|l|}{$\begin{array}{l}\text { Median months of onset } \\
\text { (range) }\end{array}$} \\
\hline BMF & $52(0-297)$ & $72(27-297)$ & $28(7-87)$ & $0(0-7)$ \\
\hline MDS/AML & $118(4-384)$ & $156(61-384)$ & $85(41-192)$ & $4(4-12)$ \\
\hline $\begin{array}{l}\text { Number of cases with } \\
\text { SCT (\%) }\end{array}$ & $58(91)$ & $33(92)$ & $23(92)$ & $2(67)$ \\
\hline $\begin{array}{l}\text { Median months at SCT } \\
\text { (range) }\end{array}$ & $\begin{array}{l}118\left(12^{-}\right. \\
448)\end{array}$ & $130(52-448)$ & $86(28-248)$ & $\begin{array}{c}25\left(13^{-}\right. \\
36)\end{array}$ \\
\hline
\end{tabular}

MDS, myelodysplastic syndrome; AML, acute myeloid leukemia; AA, aplastic anemia; SAA, severe aplastic anemia; SCT, stem cell transplantation.

${ }^{\mathrm{A}}$ Mutations found in the patients were listed in supplemental Table 1. Some of them were presumptive, since their functional significance has not been determined.

${ }^{B}$ Somatic mosaicism due to reversion was confirmed in two cases and suspected in one case.

${ }^{\mathrm{C}}$ In these cases, onset of SAA and MDS was essentially simultaneous. 
Figure 1. Effects of the ALDH2 deficiency on Japanese FA patients. (A and $B$ ) Cumulative incidence of BMF (A) or MDS/AML (B) were analyzed in 64 FA subjects. Numbers of AA, GA, and GG patients were 3, 25, and 36, respectively. (C) Cumulative incidence of BMF was analyzed in patients with confirmed biallelic FANCA mutations having protein truncations and/or large deletions $(n=12)$. Numbers of AA, GA, and GG patients were 1, 5, and 6, respectively. P-values shown were calculated by Gray's test. In (A), p-values between genotypes were $8.625 \times 10^{-7}$ (GG vs. GA), $2.107 \times 10^{-10}$ (GG vs. AA), $1.259 \times 10^{-6}$ (GA vs. AA), respectively. In (B), the difference between GG and GA subjects was not significant $(\mathrm{p}=0.4564479)$, whereas other statistical comparisons were highly significant (GG vs. AA, $2.911 \times 10^{-10}$; GA vs. AA, $8.813 \times 10^{-8}$ ). In (C), the p-values between GG and GA, GG and AA, or GA and AA were calculated as 0.001228433, 0.01430588, 0.02534732, respectively. (D) \% birth weight or (E) total number of physical abnormalities (shown in Supplemental Table 1) in 64 FA patients with three ALDH2 genotypes. Birth weight was normalized to mean weight at gestational age in Japan. Mean and SEM are indicated. Birth weight records were missing for three patients (supplemental Table 1). There was no significant difference between the $A L D H 2$ genotypes (Kruskal-Wallis test). (F) Frequency (\%) of cardiovascular, radial, thumb, skeletal, kidney, and extensive malformations in each $A L D H 2$ genotype. P-values were calculated by the Cochran-Armitage test for trend, which detects statistical significance of effects across the genotypes. The error bars represent $95 \%$ confidence intervals. 


\section{A Selfarchived copy in}

京都大学

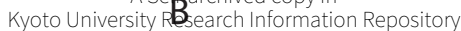
https://repository.kulib.kyoto-u.ac.jp

京都大学学術情報リポジトリ
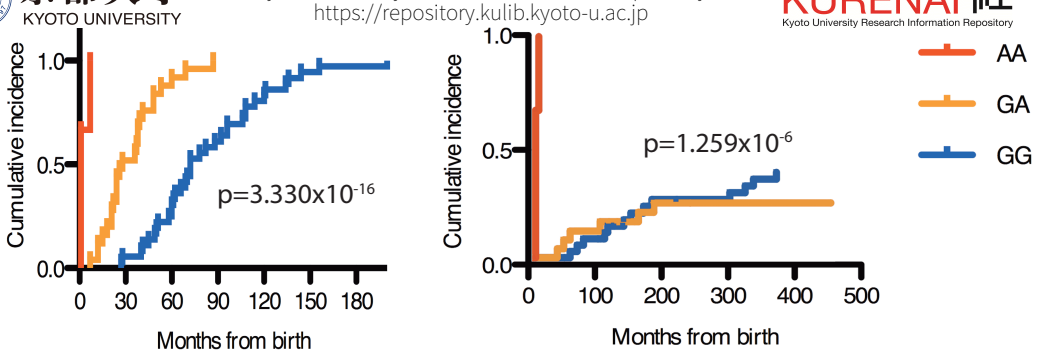

C

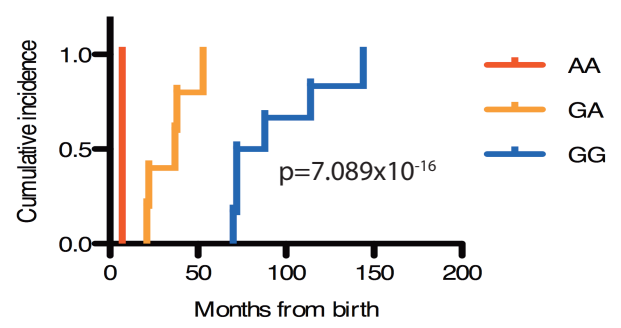

D

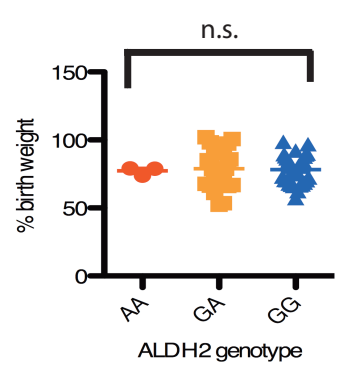

E

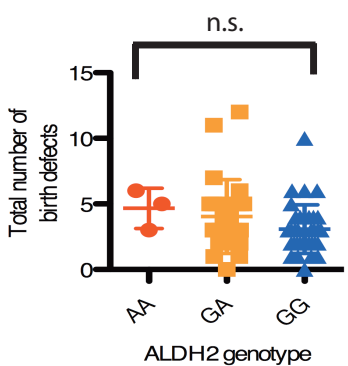

$\mathrm{F}$
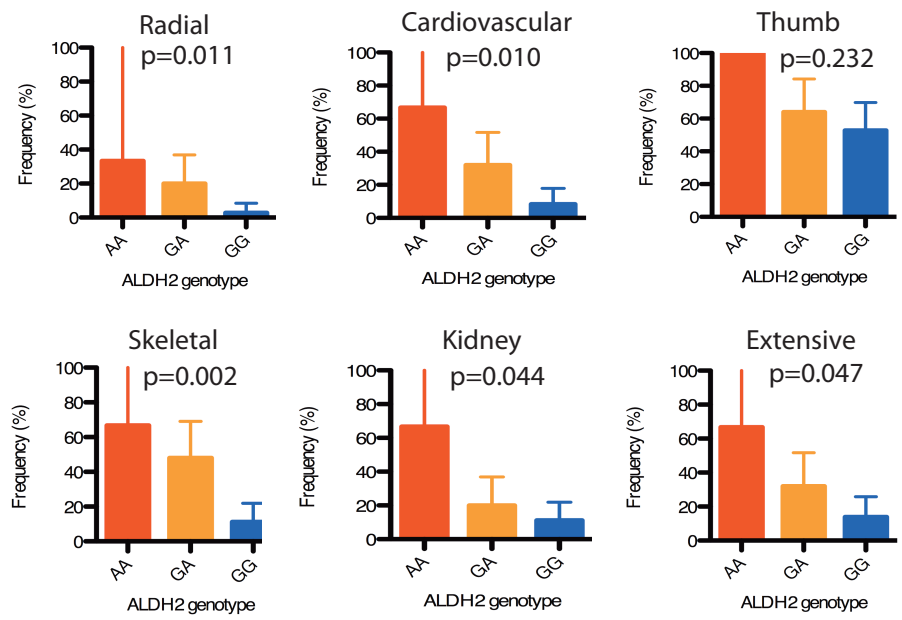

Extensive

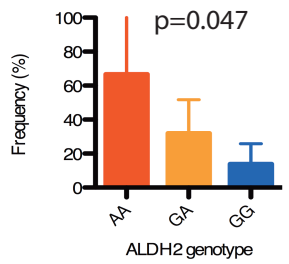




\section{Supplemental Methods}

Patients. Diagnosis of myelodysplastic syndrome (MDS) and acute myeloid leukemia (AML) is based on morphological criteria described by the FAB committee. Aplastic anemia (AA) is defined as hypoplastic marrow with two of the following: neutrophil count $<1.5 \times 10^{9} / 1$, platelet count $<100 \times 10^{9} / 1$, and hemoglobin level $<10 \mathrm{~g} / \mathrm{dl}$. Severe AA (SAA) is defined as hypoplastic marrow with two of the following: neutrophil count $<0.5 \times 10^{9} / 1$, platelet count $<20 \times 10^{9} / 1$, and reticulocyte count $<20 \times 10^{9} / 1$. The onset of BMF was defined as the time when one of the following laboratory parameter values used in the International Fanconi Anemia Registry study ${ }^{1}$ was observed: a platelet count $<100 \times 10^{9} / \mathrm{L}$, a hemoglobin level $<10 \mathrm{~g} / \mathrm{dl}$, or an absolute neutrophil count $<1 \times 10^{9} / \mathrm{L}^{1}$.

PCR, sequencing, and Taqman PCR. Genomic DNA or total RNA was isolated from either PHA-stimulated lymphocytes or cultured fibroblasts using Puregene (Qiagen) or RNAeasy (Qiagen) kits, respectively. cDNA was synthesized with a Primescript II cDNA synthesis kit (Life Technologies). Mutation analyses of cDNA and genomic DNA samples regarding FANCA, FANCC, or FANCG were carried out by PCR and direct sequencing as previously described ${ }^{2}$. In addition, 45 patients were examined by the Multiplex Ligation-mediated Probe Amplification (MLPA) test for FANCA (Falco Biosystems). Additional patients ( $\mathrm{n}=29)$ were screened by whole exome sequencing for mutations in the known 16 FA genes as described below. The $A L D H 2$ genotype was determined by a previously established Taqman-PCR assay ${ }^{3}$.

Whole exome sequencing. For exome sequencing, genomic DNA from each patient was enriched for protein-coding sequences with a SureSelect Human All Exon V4 or V5 kit 
(Agilent Technologies, Santa Clara, CA, USA). This was followed by massively parallel sequencing with the HiSeq 2000 platform with $100 \mathrm{bp}$ paired-end reads (Illumina, San Diego, CA, USA). Candidate germline variants were detected through our in-house pipeline for exome-sequencing analysis with minor modifications for the detection of germline variants ${ }^{4}$. The obtained sequences were aligned to the human reference genome (hg19) with the Burrows-Wheeler Aligner (BWA). After removal of duplicate artifacts caused by PCR, the single nucleotide variants with an allele frequency $>0.25$ and insertion-deletions with an allele frequency $>0.1$ were called. All of the identified variants in the FA genes were verified by PCR and Sanger sequencing.

\section{References}

1. Butturini A, Gale RP, Verlander PC, Adler-Brecher B, Gillio AP, Auerbach AD. Hematologic abnormalities in Fanconi anemia: an International Fanconi Anemia Registry study. Blood. 1994;84(5):1650-1655.

2. Tachibana A, Kato T, Ejima Y, et al. The FANCA gene in Japanese Fanconi anemia: reports of eight novel mutations and analysis of sequence variability. Hum Mutat. 1999;13(3):237-244.

3. Matsuo K, Wakai K, Hirose K, Ito H, Saito T, Tajima K. Alcohol dehydrogenase 2 His47Arg polymorphism influences drinking habit independently of aldehyde dehydrogenase 2 Glu487Lys polymorphism: analysis of 2,299 Japanese subjects. Cancer Epidemiol Biomarkers Prev. 2006;15(5):1009-1013.

4. Kunishima S, Okuno Y, Yoshida K, et al. ACTN1 mutations cause congenital macrothrombocytopenia. Am J Hum Genet. 2013;92(3):431-438.

5. Guardiola P, Pasquini R, Dokal I, et al. Outcome of 69 allogeneic stem cell transplantations for Fanconi anemia using HLA-matched unrelated donors: a study on behalf of the European Group for Blood and Marrow Transplantation. Blood. 2000;95(2):422-429. 
Legend for Supplemental Table 1. Clinical characteristics of the patients studied.

MDS, myelodysplastic syndrome; AML, acute myeloid leukemia; SAA, severe aplastic anemia; AA, non-severe aplastic anemia; SCT, hematopoietic stem cell transplantation; NI, not identified; WES, whole exome sequencing; MLPA, Multiplex Ligation-mediated Probe Amplification method.

${ }^{A}$ These mutations underwent reversion to wild type in lymphocytes.

${ }^{\mathrm{B}}$ These mutations were presumptive, since their functional significance has not been determined.

${ }^{\mathrm{C}}$ FA-A cases in which nonsense mutations, frame-shifts, or large deletions have been identified in both alleles. Progression of BMF in these cases was analyzed and presented in Figure 1C.

D This synonymous mutation is predicted to likely disturb normal splicing by Mutation Taster (http://www.mutationtaster.org).

${ }^{\mathrm{E}}$ Physical abnormalities included skin abnormalities (hyperpigmentation and café au lait spots), low birth weight, growth defects (short stature), and malformations (affecting thumb, radius, skeleton, head/face, eyes, ears, kidneys, gastrointestinal tract, urogenital tract and cardiovascular system). The sum of the number of physical abnormalities and the number of anatomical sites involved in malformations is presented.

${ }^{\mathrm{F}}$ Extensive malformation was defined as the involvement of at least three sites including at least one deep organ.

${ }^{\mathrm{G}}$ Genomic PCR and sequencing confirmed that the exon27 deletion detected by MLPA was caused by the mutation c.2546delC. This mutation probably abolishes the exon 27 signal because one of the MLPA probes set on exon 27 overlaps with FANCA C2546. In cases \#43 and \#59, we have not yet determined whether the Exon 27 deletion is associated with a c.2546delC mutation or not. 


\begin{tabular}{|c|c|c|c|c|c|c|c|c|c|c|c|c|c|c|c|}
\hline Patient No. & ALDH2 allele & Disease & $\begin{array}{c}\text { Defective FA } \\
\text { genes }\end{array}$ & Allele1 & Allele2 & DNA origin & WES & FANCA-MLPA & $\begin{array}{c}\text { Onset of } \\
\text { BMF(months) }\end{array}$ & $\begin{array}{c}\text { MDS or AML } \\
\text { (months) }\end{array}$ & $\begin{array}{c}\mathrm{SCT} \\
\text { (months) }\end{array}$ & $\begin{array}{c}\text { The last } \\
\text { observation } \\
\text { (months) }\end{array}$ & $\begin{array}{c}\text { Number ol } \\
\text { physical } \\
\text { abnormalities }\end{array}$ & $\begin{array}{c}\text { Extensive } \\
\text { malformation }\end{array}$ & $\%$ birth weight \\
\hline 1 & AA & MDS & $A^{c}$ & $\begin{array}{c}\text { c.2546delC } \\
\text { (p.S849FfsX40) }\end{array}$ & $\begin{array}{c}\text { c.3781_3785delT } \\
\text { TCTT } \\
\text { (p.P1261LfsX15) }\end{array}$ & Blood & & & 7 & 7 & 36 & & 3 & & 78.9 \\
\hline 2 & AA & MDS & A & $\begin{array}{c}\text { c.2546delC } \\
\text { (p.S849FfsX40) }\end{array}$ & $\mathrm{NI}$ & Blood & & & 0 & 12 & 13 & & 5 & Yes & 79.2 \\
\hline 3 & AA & MDS & $\mathrm{P}$ & $\begin{array}{c}\text { c.343delA } \\
\text { (p.S115AfsX11) }\end{array}$ & $\begin{array}{c}\text { c.343delA } \\
\text { (p.S115AfsX11) }\end{array}$ & Blood & Yes & Normal & 0 & 4 & & 6 & 6 & Yes & 73.8 \\
\hline 4 & GA & SAA & A & $\begin{array}{c}\text { c.2546delC } \\
\text { (p.S849Ffs X40) }\end{array}$ & $\mathrm{NI}$ & Blood & & & 24 & & 58 & & 5 & & 85.2 \\
\hline 5 & GA & SAA & $A^{c}$ & $\begin{array}{c}\text { c.2546delC } \\
\text { (p.S849FfsX40) }\end{array}$ & $\begin{array}{c}\text { C.3931- } \\
\text { 3932delAG } \\
\text { (p.S1311X) }\end{array}$ & Skin-fibroblast & & ex $27^{\circ} /$ & 21 & & 69 & & 6 & Yes & 61.2 \\
\hline 6 & GA & SAA & A & $\begin{array}{l}\text { c.1023G>C } \\
(p . Q 341 H)^{B}\end{array}$ & $\begin{array}{l}\text { c.1639G>T } \\
(\text { p.A547S) })^{\text {B }}\end{array}$ & Skin-fibroblast & & Normal & 24 & & 249 & & 3 & & 91.2 \\
\hline 7 & GA & MDS & A & c. $4168-2 A>G$ & $\begin{array}{c}\text { c.2546delC } \\
\text { (p.S849FfsX40) }\end{array}$ & Skin-fibroblast & & ex $27^{\oplus} /-$ & 28 & 168 & 171 & & 2 & & 69.8 \\
\hline 8 & GA & SAA/tongue cancer & $A^{c}$ & $\begin{array}{c}\text { c.2593delA } \\
\text { (p.1879LfsX24) }\end{array}$ & ex18-21 del & Blood & & ex18-21/- & 53 & & & 469 & 0 & & 71.8 \\
\hline 9 & GA & SAA & G & c. $307+1 G>C$ & c. $307+1 G>C$ & Blood & & & 38 & & 56 & & 3 & & 66.5 \\
\hline 10 & GA & SAA & $A^{c}$ & $\begin{array}{c}\text { c.2546delC } \\
\text { (p.S849FfsX40) }\end{array}$ & ex3 del & Blood & & ex27 $/$ ex $1-3$ & 22 & & 122 & & 5 & Yes & 76.4 \\
\hline 11 & GA & SAA & G & c. $307+1 G>C$ & c. $307+1 G>C$ & Blood & & & 36 & & 90 & & 2 & & 76.1 \\
\hline 12 & GA & SAA & $A^{c}$ & $\begin{array}{c}\text { c.2546delc } \\
\text { (p.S849FfsX40) }\end{array}$ & ex30 del & Blood & & $\operatorname{ex} 27^{\natural} / \mathrm{ex} 30$ & 37 & & 74 & & 1 & & 97.4 \\
\hline 13 & GA & SAA & $A^{c}$ & $\begin{array}{c}\text { c.2546delc } \\
\text { (p.S849FfsX40) }\end{array}$ & $\begin{array}{c}\text { c.2546delC } \\
\text { (p.S849Ffs X40) }\end{array}$ & BM-fibroblast & & $\operatorname{ex} 27^{\mathrm{G}} / \mathrm{ex} 27^{\mathrm{G}}$ & 38 & & 80 & & 5 & & 78.9 \\
\hline 14 & GA & MDS & $\mathrm{P}$ & $\begin{array}{l}\text { c. } 2629 \mathrm{G}>\mathrm{A} \\
\text { (p.A877T) }^{\text {B }}\end{array}$ & $\mathrm{NI}$ & Blood & Yes & Normal & 12 & 108 & 135 & & 2 & & 98.2 \\
\hline 15 & GA & MDS & G & $\begin{array}{l}\text { c.1066C>T } \\
\text { (p.Q356X) }\end{array}$ & c. $307+1 G>C$ & Blood & Yes & & 12 & 61 & 62 & & 5 & Yes & 82.9 \\
\hline 16 & GA & SAA & 1 & c. $158-2 A>G$ & $\begin{array}{l}\text { c.288G>A } \\
(p . E 96 \mathrm{E})^{\mathrm{D}}\end{array}$ & Blood & Yes & Normal & 7 & & 45 & & 11 & Yes & 52.4 \\
\hline 17 & GA & SAA & A & $\begin{array}{l}\text { c. } 1303 \mathrm{C}>\mathrm{T} \\
\text { (p.R435C) }\end{array}$ & c. $4168-1 \mathrm{G}>\mathrm{C}$ & Blood & Yes & & 26 & & 168 & & 2 & & 53.5 \\
\hline 18 & GA & MDS & M & $\begin{array}{l}\text { c. } 2330 \mathrm{~A}>\mathrm{G} \\
(\mathrm{p} . \mathrm{Y} 777 \mathrm{C})^{\mathrm{B}}\end{array}$ & $\mathrm{NI}$ & Blood & Yes & Normal & 24 & 51 & 51 & & 12 & Yes & 66.2 \\
\hline 19 & GA & SAA & G & c. $307+1 \mathrm{G}>\mathrm{C}$ & c. $307+1 \mathrm{G}>\mathrm{C}$ & Blood & Yes & Normal & 48 & & 88 & & 7 & Yes & 90.6 \\
\hline 20 & GA & SAA & G & c. $307+1 G>C$ & c. $307+1 G>C$ & Blood & Yes & & 39 & & 84 & & 5 & & 100.6 \\
\hline 21 & GA & SAA & 1 & $\begin{array}{l}\text { c.3346_3347ins } \\
\text { (p.S1116FfsX16) }\end{array}$ & c. $2826+3 A>G^{B}$ & Blood & Yes & Normal & 15 & & 28 & & 9 & Yes & 78.6 \\
\hline 22 & GA & SAA & A & c. $2602-2 A>T$ & $\begin{array}{l}\text { c.4198C }>T \\
\text { (p.R1400C) }\end{array}$ & Blood & Yes & Normal & 48 & & 154 & & 3 & & 94.9 \\
\hline 23 & GA & SAA & G & $\begin{array}{c}\text { c.907_908delCT } \\
\text { (p.L303GfsX5) }\end{array}$ & c. $307+1 G>C$ & Blood & Yes & & 21 & & 78 & & 1 & & 66.9 \\
\hline 24 & GA & SAA & G & c. $307+1 G>C$ & c. $307+1 G>C$ & Blood & Yes & & 69 & & 135 & & 4 & Yes & 74 \\
\hline
\end{tabular}




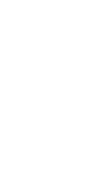

A $\quad$ c.2602-2A>T $\quad$ c.2602-2A>T Blood

\section{$\mathrm{NI}$}

ex11-15 duplication

NI

$$
\text { ex30 del }
$$

$$
\text { NI }
$$

\section{Normal}

Normal

ex27 $/ 1 / e x 33$

Normal

ex16-17/- 
Legend for Supplemental Table 2. DEB test results of the patients and control subjects.

Achromatic areas less than a chromatid in width were scored as gaps. Exchange configurations, and dicentric and ring chromosomes were scored as rearrangements. Gaps were excluded from the calculation of chromosome aberrations per cell, and rearrangements were scored as 2 breaks. 
Supplemental Table 2. DEB test results of the patients and control subjects.

\begin{tabular}{ccccc}
$\begin{array}{c}\text { Patient and } \\
\text { control } \\
\text { number }\end{array}$ & $\begin{array}{c}\text { Spontaneous } \\
\text { breakage rate } \\
\text { (breaks/cell) }\end{array}$ & $\begin{array}{c}\text { Spontaneous } \\
\text { breakage rate } \\
\text { (\% aberrant cells) }\end{array}$ & $\begin{array}{c}\text { DEB-induced } \\
\text { breakage rate } \\
\text { (breaks/cell) }\end{array}$ & $\begin{array}{c}\text { DEB-induced } \\
\text { breakage rate } \\
\text { (\% aberrant cells) }\end{array}$ \\
\hline Patient & 0.08 & 10 & 6.45 & 95 \\
2 & 0.08 & 6 & 0.44 & 37 \\
3 & 0.02 & 3 & 0.91 & 38 \\
4 & 0.02 & 2 & 1.21 & 48 \\
5 & 0.04 & 10 & 1.3 & 59 \\
6 & 0.06 & 8 & 8.32 & 100 \\
7 & 0 & 4 & 0.36 & 39 \\
8 & 0.04 & 6 & 2.28 & 38 \\
9 & 0.02 & 2 & 0.79 & 46 \\
10 & 0.02 & 14 & 0.82 & 59 \\
11 & 0.09 & 9 & 3.16 & 72 \\
12 & 0.02 & 2 & 2.66 & 33 \\
13 & 0.02 & 4 & 0.64 & 22.9 \\
14 & 0.05 & 11.5 & 0.3 & 100 \\
15 & 0.12 & 16 & 8.54 & 17 \\
16 & 0 & 0 & 0.52 & 38 \\
17 & 0.06 & 8 & 0.56 & 92 \\
18 & 0.06 & 6 & 4.2 & 92 \\
19 & 0.07 & 10 & 3.49 & 68 \\
20 & 0 & 2 & 2.36 & 52.4 \\
21 & 0.04 & 7 & 0.96 & 100 \\
22 & 0.01 & 4 & 4.07 & 99 \\
23 & 0.08 & 14 & 6.45 & 73 \\
24 & 0.01 & 1 & 6.14 & \\
25 & 0 & 2 & 2.68 &
\end{tabular}




$\begin{array}{lcccc}26 & 0 & 3 & 1.17 & 67 \\ 27 & 0.06 & 16 & 0.45 & 43 \\ 28 & 0.08 & 12 & 1.96 & 60 \\ 29 & 0 & 0 & 4.97 & 84 \\ 30 & 0.02 & 4 & 5.16 & 95 \\ 31 & 0.02 & 2 & 4.77 & 97 \\ 32 & 0 & 0 & 0.12 & 9 \\ 33 & 0 & 0 & 0.03 & 2 \\ 34 & 0.04 & 4 & 5.92 & 97.9 \\ 35 & 0 & 0 & 6.15 & 81 \\ 36 & 0.1 & 8 & 9 & 100 \\ 37 & 0.04 & 4 & 7.67 & 99 \\ 38 & 0.02 & 6 & 1.59 & 72 \\ 39 & 0.05 & 6 & 2.06 & 76 \\ 40 & 0.06 & 9 & 1.93 & 73 \\ 41 & 0 & 0 & 1.92 & 70 \\ 42 & 0.02 & 2 & 5.39 & 97 \\ 43 & 0.04 & 6 & 6.38 & 67 \\ 44 & 0 & 2 & 1.72 & 97.3 \\ 45 & 0.1 & 10 & 6.12 & 96 \\ 46 & 0.02 & 6 & 4.92 & 90 \\ 47 & 0.1 & 3 & 4.39 & 82 \\ 48 & 0.01 & 5 & 2.56 & 91 \\ 49 & 0 & 6 & 3.1 & 80 \\ 50 & 0.04 & 4 & 2.54 & 54.4 \\ 51 & 0.06 & 6 & 0.92 & 49.5 \\ 52 & 0.04 & 6 & 0.93 & 97.3 \\ 53 & 0.02 & 3.2 & 6.3 & 2 \\ 54 & 0.01 & 2 & 3.58 & 57 \\ 55 & 0.01 & 2 & 0.01 & \\ 56 & 0.01 & & 1.4 & \end{array}$




$\begin{array}{ccccc}57 & 0 & 0 & 4.85 & 93 \\ 58 & 0.01 & 4 & 0.59 & 46 \\ 59 & 0.02 & 8 & 0.67 & 36.9 \\ 60 & 0 & 0 & 0.48 & 28 \\ 61 & 0.01 & 2 & 0.89 & 35 \\ 62 & 0.49 & 52 & 3.8 & 95.7 \\ 63 & 0 & 0 & 7.8 & 100 \\ 64 & 0.09 & 9 & 2.38 & 54\end{array}$

\begin{tabular}{ccccc}
\hline Control & 0 & 0 & 0.02 & 2 \\
2 & 0 & 0 & 0.01 & 1 \\
3 & 0 & 0 & 0.01 & 5 \\
4 & 0.01 & 1 & 0.05 & 5 \\
5 & 0.01 & 1 & 0.05 & 1 \\
6 & 0 & 1 & 0.01 & 4 \\
7 & 0 & 2 & 0.04 & 4 \\
8 & 0 & 1 & 0.04 & 2 \\
9 & 0 & 0 & 0.02 & 3 \\
10 & 0 & 0 & 0.03 & 3 \\
11 & 0 & 0 & 0.02 & 4 \\
12 & 0 & 1 & 0 & 2 \\
13 & 0 & 2 & 0.02 & 1 \\
14 & 0 & 0 & 0.02 & 1 \\
15 & 0 & 1 & 0 & 4 \\
16 & 0 & 0 & 0 &
\end{tabular}




$$
1 \mathrm{H} \| \mathrm{I}
$$

